\title{
OSHA's Enforcement of Asbestos Standards in the Construction Industry
}

\author{
Christopher Allen Janicak \\ Department of Safety Sciences, Indiana University of Pennsylvania, Indiana, USA \\ Email: cjanicak@iup.edu \\ Received 6 September 2014; revised 5 October 2014; accepted 5 November 2014 \\ Copyright (c) 2014 by author and Scientific Research Publishing Inc. \\ This work is licensed under the Creative Commons Attribution International License (CC BY). \\ http://creativecommons.org/licenses/by/4.0/ \\ c) (i) Open Access
}

\section{Abstract}

Background: Exposure to asbestos continues to be a concern for workers in the construction industry. Asbestos can still be found in many construction products and in hundreds of thousands of buildings in the United States. Methods: Data from OSHA's Integrated Management Information System (IMIS) were used to identify inspections in which violations of OSHA's asbestos standards were cited from 2010 to 2012. Employers selected for analysis had NAICS codes in the construction industry sector. Descriptive statistics were used to describe the characteristics of OSHA's enforcement approach to asbestos standards violations in the construction industry. Nonparametric statistics were used to identify significant differences in penalties assessed for violating asbestos standards based upon the type of violation and the type of inspection. Results: This study identified 4017 violations from 846 inspections in which the asbestos standards were cited in the construction industry. Employee complaints and referrals resulted in the largest number enforcement activities. Significant differences were identified in the fines assessed for different types of violations and inspections. Site preparation contractors, residential construction, and commercial and institutional building construction trades experienced the greatest number of violations. Most frequently cited standards included employees performing work in areas that were not properly regulated, personal protective equipment not meeting standards, and employee training not meeting standards. Conclusions: Recommended control measures include conducting targeted inspections in construction industry trades with a greater potential exposure to asbestos, improving worker awareness of asbestos and its hazards, strengthening the fining structure for asbestos violations, and conducting further research to determine underlying reasons for employers' inability to comply with OSHA's asbestos standards.

\section{Keywords}

Asbestos, Construction Industry, OSHA, Enforcement 


\section{Introduction}

Over the years, the use of asbestos in the United States has declined substantially and mining of asbestos in the United States ceased in 2002 [1]. However, many asbestos products remain in use and new asbestos-containing products continue to be manufactured in or imported into the United States [1]. Exposure to asbestos is a great concern especially for people working in the construction industry. The presence of asbestos in construction materials from use decades ago, the continued use of asbestos containing materials not banned today in the United States, and work activities that require workers to disturb asbestos containing materials through demolition, alterations, and construction activities add up to increased chances for exposure to airborne asbestos.

To protect workers from asbestos exposure, the Occupational Safety and Health Administration (OSHA) has adopted the asbestos standards for the construction industry, 29 CFR 1926.1101 [2]. The OSHA standards apply to asbestos family of materials of chrysotile, amosite, crocidolite, tremolite asbestos, anthophyllite asbestos, actinolite asbestos, and any of these minerals that have been chemically treated and/or altered [2]. The standards do not apply to asbestos-containing asphalt roof coatings, cements and mastics [2]. The OSH Act is enforced by the federal OSHA in 29 states while 21 states have state plans which meet or exceed the requirements of federal OSHA [3].

The OSHA asbestos standards establish requirements for monitoring, measuring, and protecting workers who may potentially be exposed. Most OSHA state plan states adopted the 29 CRF 1926.1101 federal OSHA standards. Two states, California (CAL/OSHA) and Washington State (WISHA) have their own standards for asbestos in the construction industry [4].

In addition to promulgating standards, OSHA has the responsibility of ensuring safe and healthful workplaces through enforcement efforts. These workplace inspections can be initiated through a number of avenues ranging from planned inspections in which the site falls under a targeted OSHA inspection priority to employee complaints and referrals. OSHA also has established inspection priorities with their number one priority being imminent dangers followed by fatalities, catastrophes, and accidents [5]. Employers on the other hand, have the responsibility to protect their employees from the hazards of asbestos and federal OSHA and state OSHA plans have the responsibility of enforcing the asbestos safety standards. The purpose of this study was to examine the enforcement of occupational safety and health standards for asbestos in the construction industry. With a better understanding of how these standards are being enforced, recommend actions can be developed which, when implemented, can better protect workers.

\section{Methodology}

\subsection{Data}

The focus of this study was on the safety inspection and enforcement activities related to asbestos in the construction industry. Data from OSHA's Integrated Management Information System (IMIS) was analyzed for inspections conducted by the federal Occupational Safety and Health Administration and the agencies enforcing state plan occupational safety and health standards. The IMIS system contained data from both federal OSHA states and state plan states. Inspection data and violation data in which violations of OSHA's 29 CFR 1926.1101, CAL/OSHA's, Title 8 Section 1529, or WISHA's WAC 296-62-07705 were cited were included for analysis. Inspections were conducted between January 1, 2010 and December 31, 2012 involving employers with NAICS codes falling in the construction industry sector.

The following variables from the IMIS records were examined in this study:

Asbestos Standard Violated: The specific asbestos standard number that was violated was identified. The standard numbers selected for this study included OSHA's 29 CFR 1926.1101, CAL/OSHA's Title 8 Section 1529, and WISHA's WAC 296-62-077.

Penalties: The current penalty assigned to each standard violated was identified. Current penalties are the penalties assessed following any reductions or deletions from administrative actions such as informal conferences.

Type of Inspection: The type of inspection was classified as follows [6]:

Fatalities and Catastrophes - Incidents that involved a death or the hospitalization of three or more employees. 
Complaints-Allegations of hazards or violations by employees.

Referrals-Referrals of hazard information from other federal, state or local agencies, individuals, organizations or the media receive consideration for inspection.

Follow-Ups-Checks for abatement of violations cited during previous inspections conducted by OSHA in certain circumstances.

Planned or Programmed Investigations - Inspections aimed at specific high-hazard industries or individual workplaces that have experienced high rates of injuries and illnesses.

Unprogrammed Related Investigations - Inspections of employers at multi-employer work sites whose operations are not directly affected by the subject of the conditions identified in the complaint, accident, or referral.

Type of Violation: The violations were classified according to their severity according to the following OSHA classification system [5]:

Willful Violation: A willful violation exists where the evidence shows either an intentional violation of the Act or plain indifference to its requirements.

Repeat Violation: A repeated violation exists if that employer has been cited previously for a substantially similar condition and the citation has become a final order.

Serious Violation: A serious violation exists when a hazard causes or was likely to cause death or serious physical harm.

Other-Than-Serious Violation: An other-than-serious violation is cited in situations where the most serious injury or illness that would be likely to result from a hazardous condition cannot reasonably be predicted to cause death or serious physical harm to exposed employees but does have a direct and immediate relationship to their safety and health.

NAICS Code: The North American Industrial Classification System (NAICS) code for the establishment site as determined by OSHA was used to classify establishments by industry sector. The construction industry consists of industry sectors with NAICS codes that range from 230000 to 238990.

Number of Employed Persons: The number of employed persons over the three year period was obtained using the Bureau of Labor Statistics Current Population Survey.

\subsection{Statistical Analyses}

Data was analyzed descriptively to summarize the number of asbestos standard violations by industry, the type of inspection conducted, the standard number that was violated, and the type of violation. Penalties assessed for asbestos violations were summarized by type of inspection, standard number, and type of violation.

Because the distribution of penalties was not normally distributed, use of non-parametric statistical procedures was required. The Kruskal-Wallis test examines ranks across the categorical independent groups [7]. If all of the samples were from the same population, then the mixture of high, medium and low ranks should be evenly distributed across the groups [7].

The Kruskal-Wallis test was used in this study to identify the presence of significant differences in the mean rankings of penalties assessed across the different types of inspections. A second Kruskal-Wallis test was used to identify significant differences in the mean rankings of penalties assessed between the different asbestos violation categories. Post hoc Mann-Whitney U tests were used to identify significant differences between each of the pairwise groups [8].

\section{Results}

\subsection{Type of Inspections}

Data from the IMIS system identified 4017 violations from 846 inspections in which the asbestos standards were cited in construction industry establishments during the analysis period of January 1, 2010 to December 31, 2012. Employee complaints accounted for approximately 34.0 percent of all asbestos violations, referrals accounted for 22.8 percent, and planned inspections accounted for approximately 20.3 percent (see Table 1 ).

Overall, the average penalty assessed for a violation of an asbestos standard was $\$ 809$. The average penalties ranged from \$239 for violations classified as “Other-than-serious” to \$9205 for violations classified as “Willful”. A summary of the results appears in Table 2. 
Table 1. Frequency, percentage, and average penalty of asbestos violations by inspection type (2010-2012).

\begin{tabular}{cccc}
\hline & & \multicolumn{2}{l}{ Descriptive Statistics } \\
Inspection Type & $\mathrm{N}$ & Percent & Average Penalty (USD) per Violation \\
\cline { 2 - 4 } Accident & 5 & 0.1 & 343 \\
Complaint & 1365 & 34.0 & 1090 \\
Referral & 914 & 22.8 & 915 \\
Follow Up & 5 & .1 & 1040 \\
Unprogrammed-Related & 744 & 18.5 & 558 \\
Planned & 815 & 20.3 & 537 \\
Programmed-Related & 156 & 3.9 & 402 \\
Programmed-Other & 6 & .1 & 214 \\
Unprogrammed-Other & 7 & .2 & 167 \\
Total & 4017 & 100.0 & $\$ 809$ \\
\hline
\end{tabular}

Table 2. Frequency, percentage, and average penalty of asbestos violations by violation type (2010-2012).

\begin{tabular}{cccc}
\hline & \multicolumn{3}{c}{ Descriptive Statistics } \\
\cline { 2 - 4 } Inspection Type & $\mathrm{N}$ & Percent & Average Penalty (USD) per Violation \\
\hline Serious & 3196 & 79.6 & 637 \\
Other-Than-Serious & 692 & 17.2 & 239 \\
Repeat & 18 & 0.4 & 1372 \\
Willful & 111 & 2.8 & 9,205 \\
Total & 4017 & 100.0 & $\$ 809$ \\
\hline
\end{tabular}

\subsection{Violations}

An analysis of asbestos related inspections and violations identified the Site Preparation Contractor sector as having the largest percentage of asbestos inspections (20.2\%) and the largest percentage of asbestos violations (24.8\%) (see Table 3). However, this industry only accounted for less than 5 percent of all asbestos inspections and had an inspection rate of 8.29 inspections per 1000 employees which is below the overall inspection rate of 9.04 inspections per 100,000 employees. This industry comprises establishments primarily engaged in site preparation activities, such as excavating and grading, demolition of buildings and other structures, septic system installation, and house moving (BLS, 2014).

\subsection{Industry Sector}

The Commercial and Institutional Building Construction industry accounted for approximately 15.4 percent of all inspections and 19.3 percent of all inspections resulting in asbestos violations. This industry was the second highest in terms of the frequency of both all inspections and asbestos related inspections. Residential Remodelers were the third most frequently cited industry for asbestos violations accounting for approximately 12.9 percent of all asbestos inspections and 13.3 percent of all asbestos violations. However, this industry accounted for less than 3 percent of all inspections. An analysis of all inspections in construction industry NAICS code found the roofing industry accounted the most inspections overall with approximately 16.2 percent of all inspections but less than 9 percent of all asbestos violations and less than 9 percent of inspections resulting in asbestos violations. 
Table 3. Frequency, percentage, and average penalty of asbestos violations by violation type (2010-2012).

\begin{tabular}{|c|c|c|c|c|c|c|c|}
\hline \multirow[t]{2}{*}{ Industry Name and NAICS Code } & \multirow{2}{*}{$\begin{array}{c}\text { Inspections } \\
\text { per } 1000 \\
\text { Employees }\end{array}$} & \multicolumn{2}{|c|}{$\begin{array}{c}\text { All } \\
\text { Inspections }\end{array}$} & \multicolumn{2}{|c|}{$\begin{array}{l}\text { Asbestos } \\
\text { Inspections }\end{array}$} & \multicolumn{2}{|c|}{$\begin{array}{l}\text { Asbestos } \\
\text { Violations }\end{array}$} \\
\hline & & $\mathrm{N}$ & $\%$ & $\mathrm{~N}$ & $\%$ & $\mathrm{~N}$ & $\%$ \\
\hline New Single-Family Housing Construction $(236,115)$ & 6.45 & 5531 & 3.8 & 37 & 4.4 & 110 & 2.7 \\
\hline New Multifamily Housing Construction $(236,116)$ & 44.23 & 2864 & 2.0 & 10 & 1.2 & 44 & 1.1 \\
\hline New Housing For-Sale Builders $(236,117)$ & 3.26 & 225 & 0.2 & 2 & 0.2 & 8 & .2 \\
\hline Residential Remodelers $(236,118)$ & 4.71 & 3427 & 2.4 & 109 & 12.9 & 533 & 13.3 \\
\hline Industrial Building Construction $(236,210)$ & 5.49 & 2467 & 1.7 & 11 & 1.3 & 54 & 1.3 \\
\hline Commercial and Institutional Building Construction $(236,220)$ & 15.02 & 22,524 & 15.7 & 163 & 19.3 & 752 & 18.7 \\
\hline Water and Sewer Line and Related Structures Construction $(237,110)$ & 12.53 & 5725 & 4.0 & 9 & 1.1 & 47 & 1.2 \\
\hline $\begin{array}{l}\text { Power and Communication Line and Related Structures Const. } \\
\qquad(237,130)\end{array}$ & 2.09 & 873 & 0.6 & 1 & 0.1 & 3 & 0.1 \\
\hline Land Subdivision $(237,210)$ & 0.73 & 102 & 0.1 & 4 & 0.5 & 13 & 0.3 \\
\hline Highway, Street, and Bridge Construction $(237,310)$ & 8.54 & 7299 & 5.1 & 3 & 0.4 & 9 & 0.2 \\
\hline Other Heavy and Civil Engineering Construction $(237,990)$ & 6.12 & 1766 & 1.2 & 1 & 0.1 & 1 & 0.0 \\
\hline Poured Concrete Foundation and Structure Contractors $(238,110)$ & 8.52 & 2617 & 1.8 & 3 & 0.4 & 12 & 0.3 \\
\hline Structural Steel and Precast Concrete Contractors $(238,120)$ & 22.64 & 3152 & 2.2 & 1 & .1 & 2 & 0.0 \\
\hline Framing Contractors $(238,130)$ & 57.06 & 9065 & 6.3 & 16 & 1.9 & 50 & 1.2 \\
\hline Masonry Contractors $(238,140)$ & 23.63 & 9182 & 6.4 & 7 & 0.8 & 38 & 0.9 \\
\hline Glass and Glazing Contractors $(238,150)$ & 6.86 & 979 & 0.7 & 6 & 0.7 & 29 & 0.7 \\
\hline Roofing Contractors $(238,160)$ & 47.93 & 23,411 & 16.3 & 73 & 8.6 & 351 & 8.7 \\
\hline Siding Contractors $(238,170)$ & 29.00 & 2701 & 1.9 & 5 & 0.6 & 63 & 1.6 \\
\hline $\begin{array}{l}\text { Other Foundation, Structure, and Building Exterior Contractors } \\
\qquad(238,190)\end{array}$ & 8.65 & 936 & 0.7 & 3 & 0.4 & 11 & 0.3 \\
\hline $\begin{array}{l}\text { Electrical Contractors and Other Wiring Installation Contractors } \\
\qquad(238,210)\end{array}$ & 3.66 & 7909 & 5.5 & 38 & 4.5 & 161 & 4.0 \\
\hline Plumbing, Heating, and Air-Conditioning Contractors $(238,220)$ & 2.87 & 6938 & 4.8 & 59 & 7.0 & 283 & 7.0 \\
\hline Other Building Equipment Contractors $(238,290)$ & 2.74 & 974 & 0.7 & 4 & 0.5 & 21 & 0.5 \\
\hline Drywall and Insulation Contractors $(238,310)$ & 6.88 & 4046 & 2.8 & 19 & 2.2 & 35 & 0.9 \\
\hline Painting and Wall Covering Contractors $(238,320)$ & 7.16 & 3543 & 2.5 & 13 & 1.5 & 69 & 1.7 \\
\hline Flooring Contractors $(238,330)$ & 3.79 & 660 & 0.5 & 22 & 2.6 & 148 & 3.7 \\
\hline Finish Carpentry Contractors $(238,350)$ & 5.08 & 1659 & 1.2 & 5 & 0.6 & 17 & 0.4 \\
\hline Other Building Finishing Contractors $(238,390)$ & 7.82 & 1439 & 1.0 & 6 & 0.7 & 41 & 1.0 \\
\hline Site Preparation Contractors $(238,910)$ & 8.29 & 6566 & 4.6 & 171 & 20.2 & 997 & 24.8 \\
\hline All Other Specialty Trade Contractors $(238,990)$ & 6.81 & 5234 & 3.6 & 45 & 5.3 & 115 & 2.9 \\
\hline Total & 9.04 & 143,814 & 100.0 & 846 & 100.0 & 4017 & 100.0 \\
\hline
\end{tabular}

\subsection{Asbestos Standard Violated}

An analysis of violations by asbestos standard was performed for the three groups of standards; OSHA's 1926.1101 standards, CAL/OSHA's 1529 asbestos standards, and WISHA's 296-62-077 asbestos standards. During the analysis period, there were 3360 violations of the 1926.1101 asbestos standards cited. The most fre- 
quently cited sections the standards included violations of the requirements for asbestos work to be conducted in regulated areas, lack of employee training, personal protective equipment (PPE) violations, and a lack of monitoring and exposure assessment (see Table 4).

Similar results were identified for the leading CAL/OSHA 1529 standards cited. Overall, there was 123 violations of the 1529 standards with the most frequently cited sections including violations of the requirements for exposure assessment, regulated work areas, employee training, PPE, and control measures. Frequently cited violations of the WISHA standards included violations of standards pertaining to the communication of hazards, monitoring criteria, PPE, and employee training. Overall, there were 534 violations of the asbestos standards identified for the analysis period. Because of the degree of hazards associated with willful violations and the penalties they can carry, an analysis of willful violations of the asbestos standards was conducted. Most frequently cited standards in which willful violations were identified include standards pertaining to work in regulated areas, employee training, monitoring, and respiratory protection.

\subsection{Inferential Tests}

Kruskal-Wallis tests were conducted to determine if significant differences in mean rankings of penalties assessed for asbestos violations exist between the types of violations. The data met the assumptions of the test procedure as described in the Methods section. There were 4,017 cases in the analysis. The Kruskal-Wallis test identified significant differences in the mean ranks of the penalties assessed by type of violation $\left(X^{2}=133.15\right.$, d.f. $=3, \mathrm{p}<0.000$ ) (see Table 5). Post hoc tests using Mann-Whitney U tests identified significant differences between pairwise mean rankings (see Table 6). These post hoc tests identified significant differences between the mean rankings for all pairs except for the mean ranking of penalties assessed for repeat violations compared to willful violations. Significant results indicate the penalties differ significantly between groups.

Kruskal-Wallis tests also identified significant differences in the mean rankings of the penalties assessed by type of inspection $\left(X^{2}=48.49\right.$, d.f. $\left.=8, \mathrm{p}<0.001\right)$ (see Table 7). Mann-Whitney U post hoc tests identified a number of significant differences between pairs of mean rankings (see Table 8). Mean rankings for penalties assessed were significantly different for follow up inspections compared to all other types of inspections. Complaint and referral inspections penalties were significantly different. Other pairwise comparisons had mixed results.

\section{Discussion}

Exposure to asbestos poses a major health hazard to workers in the construction industry despite efforts to eliminate its use. While there have been a number of bans on the use asbestos enacted in the United States, it is still

Table 4. Most frequently cited 1926.1101 standards (2010-2012).

\begin{tabular}{ccc}
\hline Standard & N & $\begin{array}{c}\text { Percent } \\
\text { (Total N = 3360) }\end{array}$ \\
\hline Class I, II, and III asbestos work conducted in regulated areas (1926.1101 E01) & 226 & 6.7 \\
Employee training (1926.1101 K09 I) & 167 & 5.0 \\
Protective clothing (1926.1101 I01) & 160 & 4.8 \\
Initial exposure assessment (1926.1101 F02I) & 146 & 4.4 \\
Duties of employers, identify ACM materials (1926.1101 K03 I) & 118 & 3.5 \\
Competent person (1926.1101 E06) & 109 & 3.2 \\
Methods of compliance, engineering controls and work practices (1926.1101 G01) & 98 & 2.9 \\
Class III controls (1926.1101 G08III) & 92 & 2.7 \\
Class I work, less than 25 linear feet or 10 square feet (1926.1101 J02I) & 90 & 2.7 \\
Respiratory protection (1926.1101 H01) & 89 & 38.5 \\
\hline
\end{tabular}


Table 5. Mean rankings of penalties assessed by type of violation.

\begin{tabular}{ccc}
\hline Type of Violation & N & Percent Mean Rank \\
\hline Serious & 3196 & 2079.36 \\
Other-Than-Serious & 692 & 1607.84 \\
Repeat & 18 & 2877.75 \\
Willful & 111 & 243.10 \\
Total & 4017 & \\
\hline
\end{tabular}

Table 6. Mann-whitney u pairswise comparisons: significance of mean rankings of penalties by type of violation.

\begin{tabular}{cccc}
\hline Type of Violation & Serious & Other-Than-Serious & Repeat \\
\hline Serious & - & & - \\
Other-than-Serious & 0.002 & 0.000 & - \\
Repeat & 0.000 & 0.003 & 0.571 \\
Willful & 0.000 & \\
\hline
\end{tabular}

Table 7. Mean rankings of penalties assessed by type of violation.

\begin{tabular}{ccc}
\hline Type of Inspection & N & Percent Mean Rank \\
Accident & 5 & 2614.30 \\
Complaint & 1365 & 2058.07 \\
Referral & 914 & 2124.90 \\
Follow Up & 5 & 3108.30 \\
Unprogrammed-Related & 744 & 2002.21 \\
Planned & 815 & 1838.08 \\
Programmed-Related & 156 & 1802.79 \\
Programmed-Other & 6 & 1639.67 \\
Unprogrammed-Other & 7 & 1623.43 \\
Total & 4017 & \\
\hline
\end{tabular}

Table 8. Mann-whitney u pairswise comparisons: significance of mean rankings of penalities by type of inspection.

\begin{tabular}{|c|c|c|c|c|c|c|c|c|}
\hline Type of Inspection & & & & & & & & \\
\hline Accident & - & & & & & & & \\
\hline Complaint & 0.296 & - & & & & & & \\
\hline Referral & 0.352 & 0.200 & - & & & & & \\
\hline Follow Up & 0.108 & 0.052 & 0.041 & - & & & & \\
\hline Unprogrammed-Related & 0.151 & 0.242 & 0.041 & 0.014 & - & & & \\
\hline Planned & 0.085 & 0.000 & 0.000 & 0.004 & 0.001 & - & & \\
\hline Programmed-Related & 0.045 & 0.006 & 0.001 & 0.004 & 0.027 & 0.623 & - & \\
\hline Programmed-Other & 0.202 & 0.304 & 0.207 & 0.022 & 0.348 & 0.578 & 0.717 & - \\
\hline \multirow[t]{2}{*}{ Unprogrammed-Other } & 0.186 & 0.340 & 0.283 & 0.022 & 0.407 & 0.631 & 0.778 & 0.861 \\
\hline & Accident & Complaint & Referral & $\begin{array}{l}\text { Follow } \\
\text { Up }\end{array}$ & $\begin{array}{l}\text { Unprogrammed- } \\
\text { Related }\end{array}$ & Planned & $\begin{array}{l}\text { Programmed- } \\
\text { Related }\end{array}$ & $\begin{array}{l}\text { Programmed- } \\
\text { Other }\end{array}$ \\
\hline
\end{tabular}


present in many forms of construction materials found in hundreds of thousands of existing buildings. This study examined OSHA's enforcement of the asbestos standards in the construction industry.

Over the three year analysis period this study covered, OSHA cited violations of the asbestos standards over 4000 times in 809 inspections. Employers engaged in site preparation trades, which includes demolition-related activities, were cited most often. However, the inspection rate based upon the number of workers was far less than many other construction industries. It appears there is a focus by OSHA on conducting inspections in industries such as the roofing industry, framing industry, and multi-family construction industry and less of a focus on the industries identified with the higher numbers of asbestos violations. To better protect workers, industries with greater exposures to asbestos should receive a higher inspection priority.

The extent to which OSHA conducts planned inspections and enforces the asbestos standards does not appear to be representative of the potential exposure in the construction industry. It appears the majority of OSHA's enforcement activities related to the asbestos standards were the result of employee complaints and referrals. These complaints and referrals accounted for more than half of all asbestos-related inspections and violations.

For OSHA's complaint inspection process to be more effective, employees must be knowledgeable of the asbestos standards, know the hazards of asbestos exposure, have skills for recognizing asbestos sources in the workplace, and be knowledgeable of OSHA's role in enforcing standards. Education and awareness programs could strengthen the enforcement of the asbestos standards by increasing workers' awareness and action resulting in higher numbers of worker complaints and corresponding enforcement activities.

Planned inspections on the other hand, while accounting for the largest percentage of willful violations, yielded less than one quarter of all asbestos violations. To strengthen the inspection process, targeting the industry groups with planned inspections focused on asbestos could have a positive impact on protecting workers. The site preparation industry group was identified as one potential focus industry due to asbestos exposure from demolition activities. The residential construction and the commercial and institutional building construction also had a disproportionate number of inspections compared to the number of asbestos-related inspections and should also be included as a sector for increased planned inspections focused on asbestos.

An examination of penalties determined OSHA's citation and penalty process resulted in the largest penalties assessed for willful violations. The higher fines can be expected for the willful violations because OSHA's penalty system establishes this practice. Of concern, however, is the fact that willfully exposing workers to asbestos in the construction industry resulted in an average penalty that was less than $\$ 10,000$ per violation. Serious violations of asbestos standards resulted in average penalties less than \$1000. A criticism of OSHA for decades has been the penalties assessed for violating OSHA standards that do not appear to match the potential severity of the long-term effects of exposure and do not serve as a true deterrent.

To protect workers, employers are required to comply with the asbestos standards. Whether it is a federal OSHA site or a state plan site, the requirements are, for the most part, the same. In fact, for many state plan states, their standards are identical to the federal standards. An analysis of the asbestos standards cited yielded similar results across these federal and state plans. Common violations included exposing workers to asbestos because regulated areas were not established, exposure monitoring was not properly conducted, and appropriate control measures were not used. The more serious violations classified as being willful included work being conducted in areas that were not regulated, a lack of exposure monitoring, a lack of PPE, and inadequate employee training. The reasons why employers failed to comply with these standards were not within the scope of this study but should be the focus of future research.

\section{References}

[1] Centers for Disease Control and Prevention (CDC) (2011) Current Intelligence Bulletin 62: Asbestos Fibers and Other Elongate Mineral Particles: State of the Science and Roadmap for Research. Centers for Disease Control and Prevention, Washington DC. http://writingcenter.waldenu.edu/706.htm

[2] Occupational Safety and Health Administration (OSHA) (2014) 29 CRF 1926.1101: Asbestos. Washington DC.

[3] Occupational Safety and Health Administration (OSHA) (2014) Frequently Asked Questions about State Occupational Safety and Health Plans. Washington DC. https://www.osha.gov/dcsp/osp/faq.html

[4] California Division of Occupational Safety and Health (CAL/OSHA) (2014) Title 8, Section 1529: Asbestos. California Division of Occupational Safety and Health, Oakland, CA.

[5] Occupational Safety and Health Administration (OSHA) (2011) CPL 02-00-150: Field Operations Manual (FOM). 
Washington DC.

[6] U.S. Department of Labor: Occupational Safety and Health Administration (OSHA) (2014) Fact Sheet, OSHA Inspections. Washington DC.

[7] Sprent, P. and Smeeton, N. (2007) Applied Nonparametric Statistical Methods. Chapman \& Hall, Boca Raton, FL.

[8] Hayes, W. (1988) Statistics. Holt, Reinhart, and Winston, Inc., Chicago, IL. 
Scientific Research Publishing (SCIRP) is one of the largest Open Access journal publishers. It is currently publishing more than 200 open access, online, peer-reviewed journals covering a wide range of academic disciplines. SCIRP serves the worldwide academic communities and contributes to the progress and application of science with its publication.

Other selected journals from SCIRP are listed as below. Submit your manuscript to us via either submit@scirp.org or Online Submission Portal.
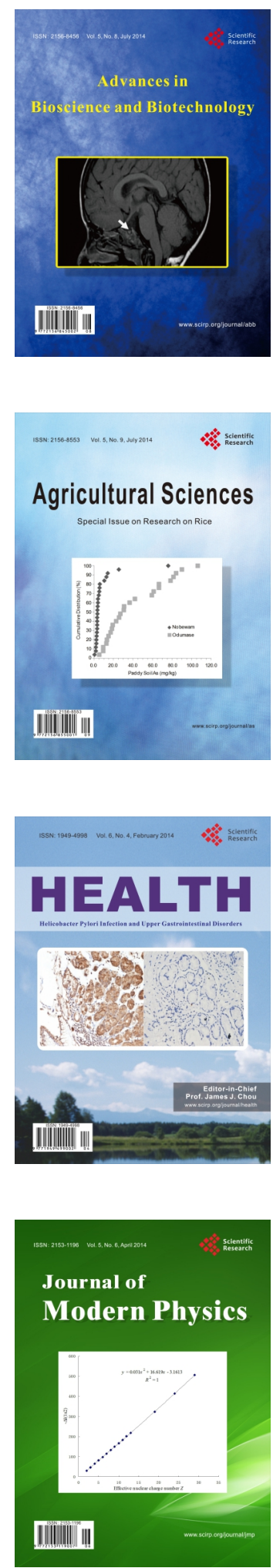
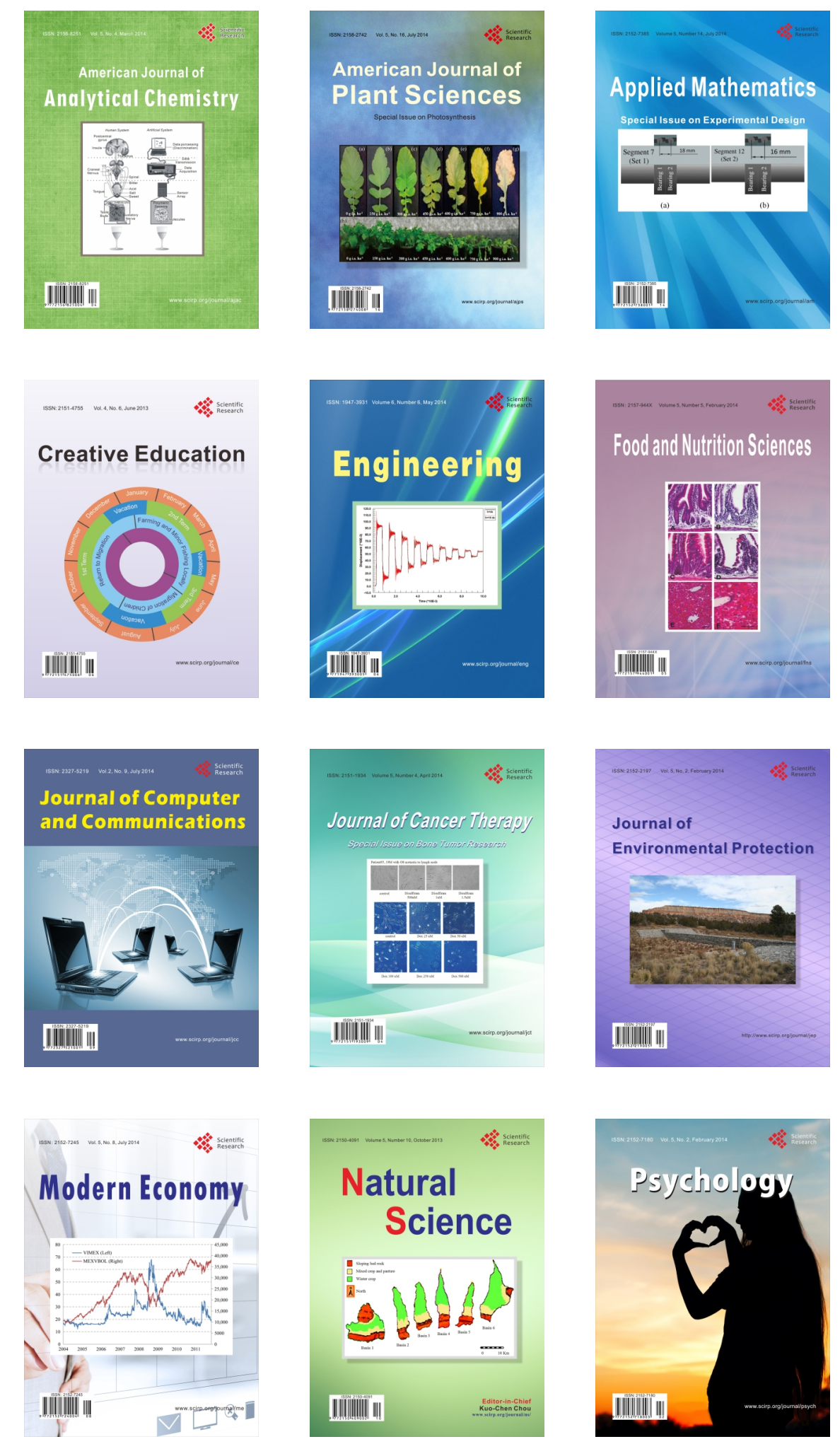